\title{
Bax regulates c-Myc-induced mammary tumour apoptosis but not proliferation in MMTV-c-myc transgenic mice
}

\author{
MH Jamerson', MD Johnson', SJ Korsmeyer², PA Furth' and RB Dickson*,I \\ 'Department of Oncology and Lombardi Comprehensive Cancer Center, Georgetown University Medical Center, 3970 Reservoir Road, NW, Washington, \\ DC 20057, USA; 'Department of Cancer Immunology and AIDS and Howard Hughes Medical Institute, Dana Farber Cancer Institute, Harvard \\ University, 44 Binney Street, Boston, MA 02115, USA
}

The expression of the proto-oncogene c-myc is frequently deregulated, via multiple mechanisms, in human breast cancers. Deregulated expression of c-myc contributes to mammary epithelial cell transformation and is causally involved in mammary tumorigenesis in MMTV-c-myc transgenic mice. c-Myc is known to promote cellular proliferation, apoptosis, genomic instability and tumorigenesis in several distinct tissues, both in vivo and in vitro. Expression of the proapoptotic regulatory gene bax is reduced or absent in human breast cancers, and c-Myc has been shown to regulate the expression of Bax, as well as cooperate with Bax in controlling apoptosis in a fibroblast model. Additionally, loss of bax reduces c-Myc-induced apoptosis in lymphoid cells and increases c-Myc-mediated lymphomagenesis in vivo. In order to assess whether loss of bax could influence c-Myc-induced apoptosis and tumorigenesis in the mammary gland in vivo, we generated MMTV-c-myc transgenic mice in which neither, one, or both wild-type alleles of bax were eliminated. Haploid loss of bax in MMTV-c-myc transgenic mice resulted in significantly reduced mammary tumour apoptosis. As anticipated for an apoptosis-regulatory gene, loss of the wild-type bax alleles did not significantly alter cellular proliferation in either mammary adenocarcinomas or dysplastic mammary tissues. However, in contrast to c-Myc-mediated lymphomagenesis, loss of one or both alleles of bax in MMTV-c-myc transgenic mice did not significantly enhance mammary tumorigenesis, despite evidence that haploid loss of bax might modestly increase mammary tumour multiplicity. Our results demonstrate that Bax contributes significantly to c-Myc-induced apoptosis in mammary tumours. In addition, they suggest that in contrast to c-Myc-induced lymphomagenesis, mammary tumorigenesis induced by deregulated c-myc expression requires some amount of Bax expression.

British Journal of Cancer (2004) 9 I, I372-1379. doi: I0.1038/sj.bjc.6602137 www.bjcancer.com

Published online 31 August 2004

(c) 2004 Cancer Research UK

Keywords: Bax; c-Myc; transgenic mice; mammary gland; apoptosis; tumorigenesis

The proto-oncogene c-myc was first identified as the mammalian homologue of the viral transforming oncogene, $\mathrm{v}-m y c$, responsible for avian myelocytomatosis (Vennstrom et al, 1982). c-Myc is a DNA-binding, nuclear transcription factor involved in the regulation of cell cycle progression, programmed cell death, cellular metabolism, and differentiation (Evan and Littlewood, 1993; Harrington et al, 1994; Packham and Cleveland, 1995). In 1994, the Dual Signal model proposed that induction of apoptosis, a potent mechanism for the suppression of tumorigenesis, was an obligate function of deregulated c- $m y c$ expression; however, more recent experimentation suggests that c-Myc may sensitise cells to apoptosis as a result of alterations in mitochondrial membrane permeability and movement of holocytochrome $c$ into the cytoplasm from its typical position as a constituent of the electron transport system (Juin et al, 1999; Prendergast, 1999). Experiments examining the cooperation of cMyc and knockouts of $\mathrm{p} 19^{\mathrm{ARF}}$ and/or p53 in mouse embryo

*Correspondence: Dr RB Dickson; E-mail: DicksonR@georgetown.edu Received 4 February 2004; revised 16 July 2004; accepted 23 July 2004; published online 31 August 2004 fibroblast models have suggested that suppression of c-Mycinduced apoptosis may facilitate malignant transformation and tumorigenesis (Zindy et al, 1998). c-Myc may increase genomic instability and enhance tumorigenesis without an absolute requirement for continued aberrant c-myc expression once additional transforming genetic lesions have been generated and fixed in the genome (Felsher and Bishop, 1999a, b). Deregulated or aberrant expression of $c-m y c$, via mechanisms including translocation, proviral insertion, locus amplification, point mutation, direct transcriptional and translational effects, or post-translational modifications, is a signature of several different human tumour types and $c-m y c$ can induce tumorigenesis under conditions where programmed cell death is abrogated (Evan et al, 1992; Santoni-Rugiu et al, 1998; Dang, 1999). The relevance of aberrant c-myc expression to the pathogenesis of breast cancer is confirmed by the finding that the c-myc locus is rearranged in roughly $5 \%$, amplified in $16 \%$, and overexpressed in approximately $70 \%$ of human breast tumours (Nass and Dickson, 1997; Deming et al, 2000).

The role of $c-m y c$ expression in normal mammary gland development and function as well as mammary tumorigenesis is a burgeoning field of inquiry. Several in vitro studies have 
demonstrated a contributory role for c-Myc in transformation of both human and murine mammary epithelial cells (MECs) (Leder et al, 1986; Telang et al, 1990; Valverius et al, 1990). Examination of normal murine mammary development has indicated that $\mathrm{c}-\mathrm{Myc}$ is expressed during pregnancy-associated proliferation and postlactational involution associated MEC apoptosis (Strange et al, 1992). To further evaluate the role of c-Myc in mammary development, function, and transformation, a transgenic mouse was generated expressing the murine $c-m y c$ gene under the control of the mouse mammary tumour virus long terminal repeat (MMTV-LTR) promotional elements (Stewart et al, 1984). MMTV-c-myc transgenic mice develop mammary adenocarcinomas in both the virgin state $(\sim 50 \%$ incidence following a $7-14$ month latency) and the multiparous state ( $\sim 100 \%$ incidence with two or more pregnancies); however, the extended mammary tumour latencies and low mammary tumour multiplicities suggest that $c-m y c$ is contributory to but insufficient for mammary tumorigenesis in the mouse (Stewart et al, 1984; Leder et al, 1986). The conditional expression of $c-m y c$ in the mammary glands of mice using an MMTV-LTR-driven tetracycline-responsive transgenic system has provided evidence for cooperative, transforming genetic alterations that may result from c-Myc-induced genomic instability (D'Cruz et al, 2001). Furthermore, the use of spectral karyotyping (SKY) and comparative genomic hybridisation (CGH) to demonstrate that MMTV-c-myc-induced mammary tumours display distinct, repeatable patterns of chromosomal alterations suggests that c-Myc may exert a dominant genomic mutator effect and that specific genetic lesions may cooperate in MEC transformation (reflecting the multistage nature of human tumorigenesis) (Weaver et al, 1999).

TGF $\alpha$, a soluble growth factor of the epidermal growth factor family of ligands, is a potent survival and growth factor for human and murine MECs both in vivo and in vitro, and when overexpressed in the mammary glands of transgenic mice, induces mammary alveolar hyperplasias and occasional mammary adenocarcinomas (Bates et al, 1990; Jhappan et al, 1990; Matsui et al, 1990; Sandgren et al, 1990; Snedeker et al, 1991; Amundadottir et al, 1995). The prosurvival molecule Bcl-2 has been shown to be expressed in the normal human and murine mammary epithelium, to impede mammary gland involution when expressed as an exogenous transgene, and to suppress $c-m y c$-induced apoptosis and cooperate with c-myc expression in inducing B-cell malignancies in another transgenic model (Bargou et al, 1995; Schorr et al, 1999a, b; Feuerhake et al, 2000; Eischen et al, 2001b). The importance of suppression of apoptosis in c-myc-induced murine mammary tumorigenesis has been suggested by three independently generated transgenic mouse models: MMTV-c-mycl MT- $t g f \alpha$, WAP-c- $m y c /$ WAP-tgf $\alpha$, and MMTV-c-myc/WAP- $b c l 2$ (Amundadottir et al, 1995; Sandgren et al, 1995; Jäger et al, 1997). Data from these three mammary bitransgenic studies strongly suggest that mammary tumorigenesis is significantly enhanced when deregulated $c-m y c$ expression, responsible for driving both proliferation and apoptosis, is coupled with alterations that block c-myc-mediated apoptotic pathways.

Bax, a proapoptotic member of the Bcl-2 family of proteins, was first discovered in a screen of proteins that exhibited binding interactions with Bcl-2 (Oltvai et al, 1993). Bax is likely to have pore-forming activity in the mitochondrial membranes, subject to control or prevention by association with specific antiapoptotic molecules (especially Bcl-2 and Bcl- $\mathrm{x}_{\mathrm{L}}$ ), related to its ability to bind to $\mathrm{BH}-3$ domain-only containing Bcl-2 family member proteins, and induce the release of mitochondrial cytochrome $c$ (Antonsson et al, 1997; Jurgensmeier et al, 1998; Desagher et al, 1999; Murphy et al, 1999; Antonsson et al, 2000; Nouraini et al, 2000; Wei et al, 2001). Bax is weakly expressed or absent in several breast cancer cell lines and transfection of bax into these lines results in increased apoptotic sensitivity and diminished tumour proliferation in athymic mice (Bargou et al, 1995, 1996; Sakakura et al,
1996). Bax is expressed in the epithelium of the normal breast and its expression is highest during postlactational mammary gland involution; furthermore, Bax expression is significantly reduced or absent in invasive ductal breast carcinomas (Krajewski et al, 1994; Bargou et al, 1995; Li et al, 1996; Feuerhake et al, 2000; Shilkaitis et al, 2000). Significant reductions in Bax expression were found in $34 \%$ of primary breast tumours in women with metastatic disease, Bax expression was inversely correlated with overall survival, treatment response, and metastasis in these patients, and Bax expression was found to be predictive of tumour response to chemotherapy independent of other predictive variables (Krajewski et al, 1995; Kapranos et al, 1997; Sjöström et al, 1998).

The mechanisms by which c-Myc induces apoptosis and the manner in which this apoptosis contributes to tumour suppression are largely unknown and currently being explored. Recently, bax was determined to be transcriptionally regulated by c-Myc in a variety of human cell lines (including the $\mathrm{SkBr} 3$ human breast cancer cell line) and found to be critical for the induction of apoptosis by aberrant c-Myc expression in a mouse embryo fibroblast model system (Mitchell et al, 2000). Two other studies indicate that c-Myc, at least in embryo fibroblast systems, activates a proapoptotic function in Bax and induces an apoptotic program that requires $\mathrm{Bax}$ (or a $\mathrm{BH} 3$ domain peptide) to be present in the mitochondrial membrane (Soucie et al, 2001; Juin et al, 2002). In addition, bax-deficient primary pre- $\beta$ cells have been shown to be resistant to proapoptotic effects of c-Myc. Furthermore, in a transgenic mouse model, loss of one or both bax allele(s) significantly accelerate c-Myc-dependent lyphomagenesis in a bax gene dosage-dependent manner (Eischen et al, 2001a). The partial or total loss of bax in knockout mice provides evidence that the presence of Bax is unlikely to be required for mammary gland development and secretory differentiation (a very small percentage of bax-nullizygous mice did evidence postpartum lactational incompetency); however, loss of bax did reduce MEC apoptosis during postlactational involution (Knudson et al, 1995; Schorr et al, 1999a, b). Loss of bax (reflecting the in vivo situation of human breast cancer patients) may disrupt c-Myc-induced apoptotic programs in mammary epithelial cells and has the potential to diminish the tumour suppressive activity of c-Myc-induced apoptosis. In this study, we have generated a combinatorial, mammary-relevant transgenic model, $b a x$-knockout/MMTV-c- $m y c$ transgenic, to examine the influence of allelic bax loss on c-Mycinduced apoptosis and tumorigenesis in vivo.

\section{MATERIALS AND METHODS}

\section{Transgenic and knockout mice}

All animal experiments were conducted in accordance with US and UK CCR guidelines (Workman et al, 1998) and in accordance with our institutionally approved protocol. MMTV-c-myc transgenic mice (FVB inbred genetic background) were obtained from Charles River Laboratories, bred under a license from DuPont Medical Products, and housed as previously described (Amundadottir et al, 1995). The MMTV-c-myc transgenic mice contain a mouse mammary tumour virus long terminal repeat promoter element driving the expression of a murine c-myc gene (Stewart et al, 1984). Mice hemizygous for bax (C57BL/6 inbred genetic background) were obtained from SJ Korsmeyer via PA Furth at Georgetown University (Knudson et al, 1995). P generation myc mice were bred to $\mathrm{P}$ generation bax-hemizygous mice and subsequently, their $F_{1}$ generation offspring were backcrossed with $\mathrm{P}$ generation bax-hemizygous mice, resulting in $\mathrm{F}_{2}$ generation offspring in which the myc transgene was found in the context of no, one, or two intact wild-type bax alleles. All data reported herein were generated using $\mathrm{F}_{2}$ generation study mice on the mixed genetic background (C57BL/6 $\times$ FVB; 3:1). Parous 
study mice, 10 weeks old, were housed with males and repetitively bred until euthanisation; all surviving pups were weaned at day 20 postpartum. Female parous study mice were examined bi-weekly for tumours and morbidity and euthanased if they showed signs of ill health using approved methods (Workman et al, 1998).

\section{Genotyping}

Overnight digestion of mouse tail biopsy samples (Workman et al, 1998) in STE buffer $(0.1 \mathrm{M} \mathrm{NaCl}, 0.05 \mathrm{M}$ Tris $\mathrm{pH} 8.0,1 \mathrm{~mm}$ EDTA, and $1 \% \mathrm{SDS}$ ) containing $5 \mathrm{mg} \mathrm{ml}^{-1}$ fungal proteinase $\mathrm{K}$ (Invitrogen, Carlsbad, CA, USA), followed by phenol/chloroform extraction and ethanol precipitation yielded genomic DNA subsequently used in genotyping of all mice utilised in this study. PCR-based genotyping was performed on a Stratagene Robocycler Gradient 40 machine using tail-derived genomic DNA, sequence-specific primers, and Platinum PCR Supermix (Invitrogen). MTVMyc $5^{\prime}$ primer $\left(5^{\prime}\right.$-CCC AAG GCT TAA GTA AGT TTT TGG-3') and MTVMyc $3^{\prime}$ primer $\left(5^{\prime}\right.$-GGG CAT AAG CAC AGA TAA AAC ACT$\left.3^{\prime}\right)$ were used to identify MMTV-c-myc transgenic mice (1 min denaturation at $95^{\circ} \mathrm{C}, 1 \mathrm{~min}$ annealing at $52^{\circ} \mathrm{C}$, and $75 \mathrm{~s}$ elongation at $72^{\circ} \mathrm{C}$ for a total of 42 cycles); transgene-positive animals were identified by resolution of a single $\sim 880 \mathrm{bp}$ band on a $1.0 \%$ agarose gel. BPR2 primer ( $5^{\prime}$-GTT GAC CAG AGT GGC GTA GG$\left.3^{\prime}\right)$, MK1 primer $\left(5^{\prime}-\right.$ GAG CTG ATC AGA ACC ATC ATG-3'), and NRP2 primer (5'-CCG CTT CCA TTG CTC AGC GG-3') were used to determine the allelic status of bax $\left(45 \mathrm{~s}\right.$ denaturation at $94^{\circ} \mathrm{C}$, $90 \mathrm{~s}$ annealing at $55^{\circ} \mathrm{C}$, and $2 \mathrm{~min}$ elongation at $72^{\circ} \mathrm{C}$ for a total of 35 cycles); animals with bax in the wild-type configuration demonstrate a single $\sim 300 \mathrm{bp}$ band, animals nullizygous for bax demonstrate a single $\sim 506 \mathrm{bp}$ band, and animals hemizygous for bax demonstrate both bands on a $1.0 \%$ agarose gel.

\section{Mammary gland tumour collection, histopathology, and whole-mount preparation}

Mammary gland tumours and tissues were freshly collected via routine dissection procedures and split for fixation, liquid $\mathrm{N}_{2}$ snap-freezing (for molecular analyses), and whole-mount preparation. Mammary gland tumours and tissues were fixed in $10 \%$ neutral-buffered formalin (EM Sciences, Gibbstown, NJ, USA) in phosphate-buffered saline (PBS), embedded in paraffin, and sectioned by microtomy to $5 \mu \mathrm{M}$. Mammary tumour and tissue sections were stained using haematoxylin and eosin and were subjected to histopathological evaluation using light microscopy. Mammary gland tissues for whole-mount preparation, routinely taken from the inguinal glands unless otherwise tumour involved, were fixed in $75 \%$ ethanol $/ 25 \%$ glacial acetic acid, stained in a $0.2 \%$ carmine alum (Sigma, St Louis, MO, USA) $/ 0.5 \%$ aluminum potassium sulfate solution, dehydrated through an ethanol series, cleared in toluene, mounted using Permount (Fisher, Fair Lawn, $\mathrm{NJ}, \underline{\mathrm{USA}}$, and examined using dissecting stereomicroscopy.

\section{Western blot analyses}

Mammary gland tumour and tissue samples that were harvested from the study mice were immediately snap-frozen in liquid $\mathrm{N}_{2}$, stored at $-80^{\circ} \mathrm{C}$, and later thawed in a RIPA homogenisation solution $(\times 1$ PBS containing $1 \%$ NP- $40,0.5 \%$ sodium-deoxycholate, $0.1 \% \mathrm{SDS}$, and $10 \mu \mathrm{g} \mathrm{ml}^{-1} \mathrm{PMSF}$ ). Briefly, samples were weighed, ground into a fine powder under liquid $\mathrm{N}_{2}$, lysed for $15 \mathrm{~min}$ on ice in a five-fold volume of RIPA solution, and centrifuged at $\sim 10000 \mathrm{~g}$ for $15 \mathrm{~min}$ at $4^{\circ} \mathrm{C}$. Supernatants were recovered after high-speed centrifugation and subject to protein concentration quantification via BCA Protein Assay (Pierce, Rockland, IL, USA). Protein lysates were then combined with $\times 4$ Laemmli Sample buffer (final concentration $50 \mathrm{~mm}$ Tris- $\mathrm{HCl}$ $\mathrm{pH} 6.8,100 \mathrm{~mm}$ dithiothreitol, $10 \%$ glycerol, $0.1 \%$ bromophenol blue, $2 \%$ SDS), boiled for $10 \mathrm{~min}$, fractionated through $12 \%$ Trisglycine gels (Invitrogen) under reducing conditions, transferred onto Immobilon-P membranes (Millipore, Bedford, MA, USA), and blocked in $1 \times$ PBS containing $5 \%$ milk and either $0.3 \%$ Tween-20 for c-Myc detection or $0.05 \%$ Tween-20 for Bax detection. For Western analysis, blots were incubated for $1 \mathrm{~h}$ at room temperature with anti-c-Myc (C-19) or anti-Bax (N-20) antibodies from Santa Cruz Biotechnology (Santa Cruz, CA, USA), washed repeatedly, and incubated in horseradish peroxidase (HRP)-conjugated secondary antibodies (NA934 from Amersham, Buckinghamshire, UK or 611-1302 from Rockland, Gilbertsville, PA, USA for c-Myc; SC-2004 from Santa Cruz). Protein visualisation was achieved using the ECL Western Blotting Reagent Kit (Amersham) and Hyperfilm-ECL photographic film (Amersham).

\section{Apoptosis and cell proliferation assays}

Formalin-fixed, paraffin-embedded mammary tumours were sectioned by microtomy and subsequently utilised to assess the presence and extent of apoptosis in the tumours and surrounding mammary tissues. The terminal deoxynucleotidyl transferase (TdT)-mediated dUTP nick end-labeling (TUNEL) method was used to evaluate apoptosis in these sections (ApopTag Peroxidase In situ Apoptosis Detection Kit, Serologicals, Norcross, GA, USA). Briefly, sections were cleared in xylene, rehydrated through an ethanol series, treated with Autozyme Digestion reagent (Biomeda, Foster City, CA, USA), and quenched in $0.15 \% \mathrm{H}_{2} \mathrm{O}_{2}$ (Sigma). The $\mathrm{TdT}$ reaction was allowed to proceed at room temperature, under humidified conditions, for $40 \mathrm{~min}$ and a peroxidase-conjugated anti-digoxigenin antibody was used to assess digoxigenin-dUTP incorporation. A diaminobenzidine/urea chromogen substrate system (Sigma) was used to visualise the TUNEL labeling reaction. Sections were counterstained in $0.5 \%$ methyl green dye (Trevigen, Gaithersburg, MD, USA), washed in $100 \%$ butanol, and mounted using DPX mountant (Electron Microscopy Sciences). Histological assessment of apoptosis, leading to the calculation of apoptotic index values, was conducted by counting the number of TUNELpositive apoptotic cells out of $>1000$ cells in contiguous highpowered $(\times 40)$ fields.

Formalin-fixed, paraffin-embedded mammary tumours were sectioned by microtomy, stained with haematoxylin, and utilised to assess the presence and extent of cell proliferation in the tumours and surrounding mammary tissues. Histological assessment of cell proliferation, leading to the calculation of mitotic index values, was conducted by counting the number of mitotic figures out of $>1000$ cells in contiguous high-powered $(\times 40)$ fields.

\section{Statistical analyses}

To evaluate the significance of differences in tumour apoptosis and proliferation between genotypes, all data were subjected to analysis of variance (ANOVA) and Scheffe post hoc testing. A KaplanMeier curve was generated for the tumour incidence data for the parous study mice and tumour incidence differences between genotypes were assessed using a generalised Wilcoxon test. Analysis of variance testing was utilised to evaluate the significance of tumour multiplicity differences between genotypes.

\section{RESULTS}

Loss of allelic bax alters mammary tumour multiplicity in parous MMTV-c-myc transgenic mice

In order to assess the influence of loss of allelic bax on c-Mycinduced apoptosis and tumorigenesis in the mammary gland, 10week-old female study mice ( $m y c b a x+I+, n=10$; myc bax $+I-$, $n=9 ;$ myc bax $-I-, n=10$ ) were housed with male mice, bred 
repetitively, and followed bi-weekly for evidence of mammary tumour development. Parous study mice were euthanised when mammary tumour burden approached $10 \%$ of animal body mass or when mice reached 1 year of age (in accordance with US and UKCCR guidelines, Workman et al, 1998). Loss of one wild-type bax allele in parous c-myc transgenic mice elevated mammary tumour multiplicity (2.75 tumours/mouse $v s 1$ tumour/mouse; $P$ -0.04 by ANOVA) as compared to parous $c-m y c$ transgenic mice in which bax was intact or completely eliminated (Figure 1A). A nonsignificant trend towards increased mammary tumour incidence was found for parous MMTV-c-myc transgenic/bax-hemizygous mice (44.4 vs 20 and $20 \% ; P=0.39$ by Wilcoxon) as compared to parous c-myc transgenic mice in which bax was intact or completely eliminated (Figure 1B). Mammary tumour latency and parity at time of mammary tumour development were not altered by loss of allelic bax in parous MMTV-c-myc transgenic mice (data not shown).

Mammary gland whole-mount and haematoxylin and eosinstained tissue sections were examined for evidence of mammary
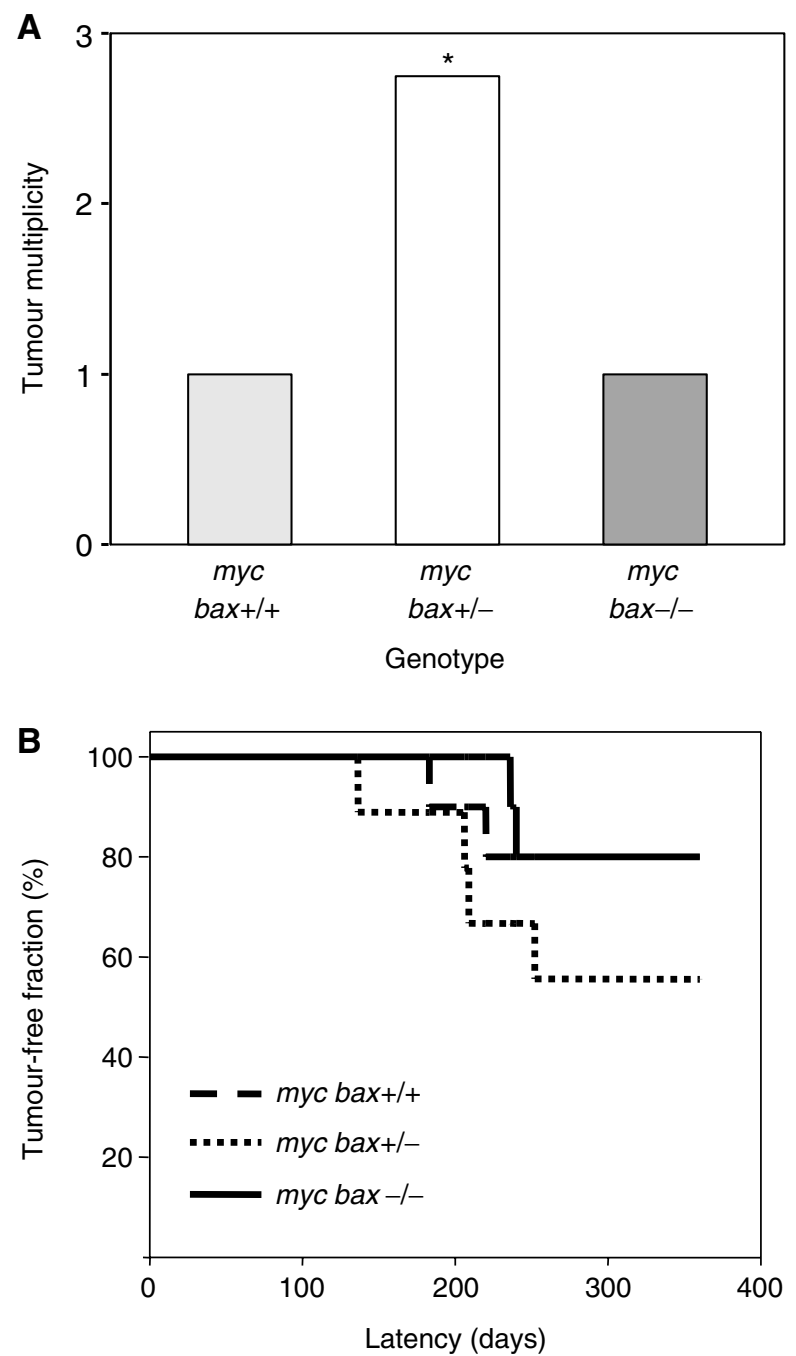

Figure I Loss of bax influences mammary tumour multiplicity but not mammary tumour incidence in parous MMTV-c-myc transgenic/baxknockout mice. (A) Mammary tumour multiplicity was increased in parous MMTV-c-myc/bax-hemizygous transgenic mice ( $*=0.04$ by ANOVA). (B) Kaplan-Meier analysis by genotype demonstrates a nonsignificant trend toward decreased tumour-free incidence with bax-hemizygosity in parous MMTV-c-myc transgenic/bax-knockout mice $(P=0.39$ by generalised Wilcoxon testing). histopathology. Assessment of mammary gland whole-mounts demonstrated that hyperplastic alveolar nodular changes were present only in mammary glands from tumour-bearing, c-myc transgene-positive study mice and were not qualitatively different with loss of allelic bax (data not shown). Microscopic histopathological assessment of the sections indicated that the mammary tumours that developed in the parous MMTV-c-myc study mice were cribiform glandular adenocarcinomas as previously described for MMTV-c-myc mammary tumours (Cardiff et al, 2000). Furthermore, loss of allelic bax, in parous MMTV-c-myc study mice, did not alter the histopathological character of these mammary tumours nor of the peri-tumorous dysplastic mammary lesions (data not shown).

\section{c-Myc and Bax expression in mammary tumours and tissue from parous MMTV-c-myc transgenic mice}

The incidence of mammary tumours in MMTV-c-myc transgenic mice, on the FVB inbred genetic background, has been reported to be approximately $50 \%$ for virgin female mice and approaching $100 \%$ for multiparous female mice (Stewart et al, 1984; Amundadottir et al, 1995). The overall mammary tumour incidence for multistrain (C57BL/6 $\times \mathrm{FVB} ; 3: 1)$, multiparous, c-myc transgenepositive study mice were $27.6 \%$, considerably lower than previously reported. Western blot analysis was utilised to determine the expression status of the MMTV-c-myc transgene in the mammary tumours and mammary gland tissue from parous study mice (c-myc transgene-negative mice were included as an assay negative control). c-Myc protein expression was only
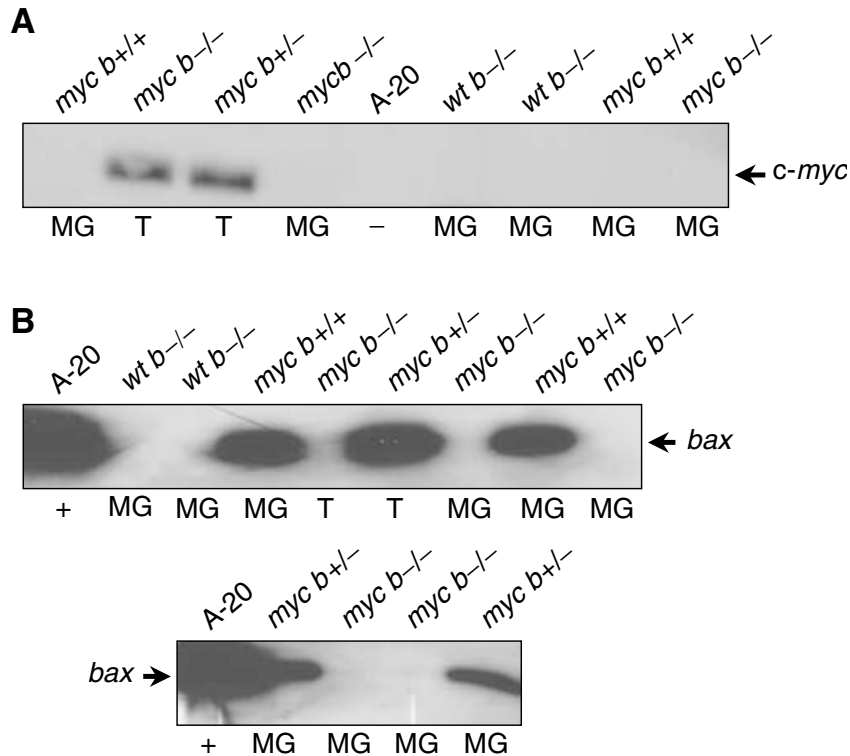

Figure 2 Western blot analysis of transgenic c-Myc protein expression and Bax protein expression in mammary tumours and mammary gland tissues from parous MMTV-c-myc transgenic/bax-knockout mice. Protein lysates were prepared from mammary tumours ( $T$ lanes), mammary gland tissues (MG lanes), and from the A-20 murine lymphoblast cell line (Bax protein positive control). (A) Western blot analysis demonstrates expression of c-Myc protein only in mammary tumour lysates from cmyc transgene-positive parous study mice. (B) Western blot analysis demonstrates that expression of Bax protein is lost in tumour and mammary gland tissue lysates from bax-nullizygous parous study mice, that expression of Bax protein is reduced in mammary gland tissue lysates from bax-hemizygous parous study mice as compared with bax-intact mice, and confirms that bax loss of heterozygosity is not evident in mammary tumours from parous MMTV-c-myc transgenic/bax-hemizygous study mice (Western blots were run simultaneously under identical conditions with mammary gland tissue lysates equally loaded for the amount of protein). 
detectable in lysates from mammary adenocarcinomas and not in lysates from nontumorous mammary gland tissue from c-myc transgene-positive mice (Figure $2 \mathrm{~A}$ and data not shown).

Western blot analysis confirmed that Bax protein expression was absent in mammary tumour and mammary gland tissue lysates from parous study mice nullizygous for bax (Figure 2B). Western blot analysis also confirmed that Bax protein expression was reduced in mammary gland tissue lysates (equally loaded for protein and run simultaneously under identical conditions) prepared from bax-hemizygous parous study mice as compared to $b a x$-intact parous study mice (Figure $2 \mathrm{~B}$ ). Loss of heterozygosity (LOH) for bax was not found to be a part of mammary tumour development and progression in the C3(1)/SV40-Tag transgenic/ bax-hemizygous murine tumour model (Shibata et al, 1999) nor in malignancies arising in arf-nullizygous/bax-hemizygous mice (Eischen et al, 2002). Bax LOH was not found in mammary tumour development in parous MMTV-c-myc transgenic/baxhemizygous mice (Figure 2B and data not shown).

\section{Loss of allelic bax significantly diminishes mammary tumour apoptosis in parous MMTV-c-myc transgenic mice}

Apoptotic indices were generated for both mammary adenocarcinomas and peri-tumorous dysplastic lesions by counting TUNELpositive cell on mammary tumour and tissue sections. As shown in Figure 3, apoptosis was significantly decreased in mammary adenocarcinomas with loss of allelic bax in parous MMTV-c-myc study mice $(9.05 \pm 1.12$ for $m y c b a x+I+v s 7.38 \pm 0.17$ for $m y c$ $b a x+I-v s 5.48 \pm 0.28$ for myc bax $-I-)$; furthermore, a trend toward diminished apoptosis was seen in mammary dysplastic lesions with loss of allelic bax in parous MMTV-c-myc study mice $(7.20 \pm 1.30$ for $m y c b a x+I+v s 4.17 \pm 0.50$ for $m y c b a x+I-v s$ $2.29 \pm 0.71$ for myc bax-/-). In mammary adenocarcinomas, the levels of apoptosis were significantly different for each of the three evaluated genotypes $(P=0.001$ for $m y c b a x+I+v s$ myc bax $+I-$; $P=0.033$ for $m y c b a x+I-v s$ myc bax $-I-$; and $P=0.017$ for $m y c$ $b a x+I+v s$ myc bax $-I-)$ as well as between the adenocarcinomas and dysplastic mammary lesions in tumour-bearing, parous MMTV-c-myc/bax-hemizygous study mice $(P=0.001)$.

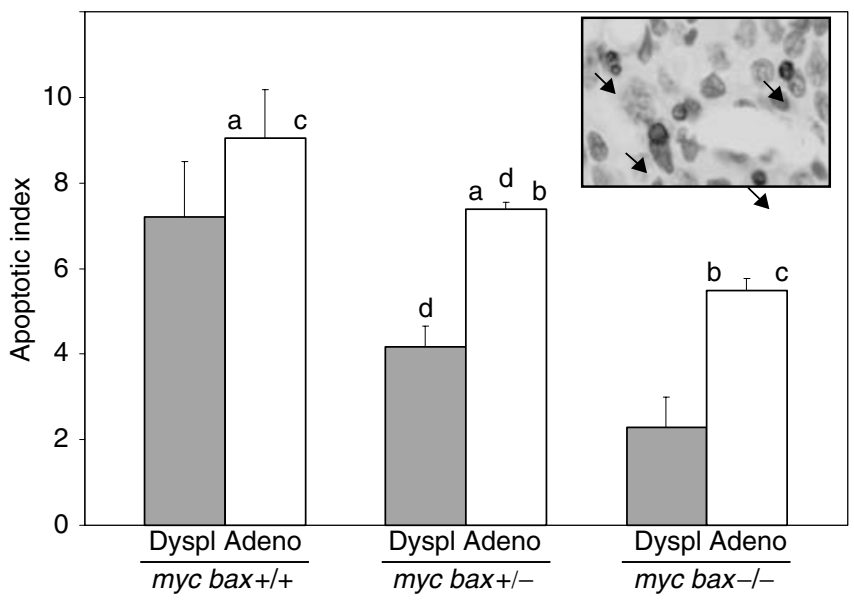

Figure 3 Apoptosis is significantly decreased in mammary adenocarcinomas from parous MMTV-c-myc transgenic/bax-knockout mice with loss of each wild-type allele of bax. A trend toward decreased apoptosis, with loss of allelic bax, is seen for mammary dysplastic lesions. Data are presented as mean apoptotic index \pm s.e.m. and significance comparisons were conducted by ANOVA and Scheffe post hoc testing: a $(P=0.00 \mathrm{I}), \mathrm{b}$ $(P=0.033), c(P=0.017)$, and $d(P=0.00 \mathrm{I})$. (Inset) Histological image of TUNEL-stained mammary section with black arrowheads indicating representative TUNEL-positive apoptotic cells.

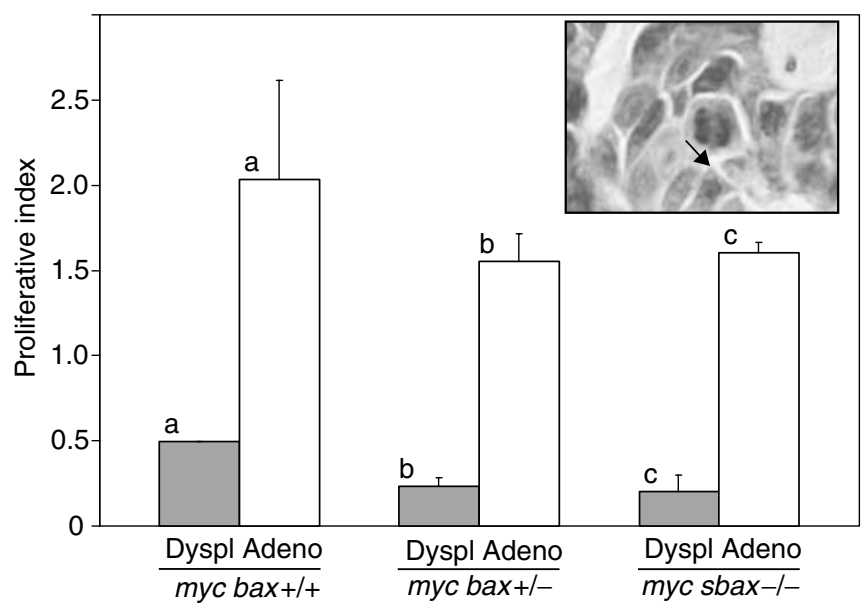

Figure 4 Cellular proliferation is not significantly altered, with loss of allelic bax, in mammary adenocarcinomas and mammary dysplastic lesions from parous MMTV-c-myc transgenic/bax-knockout mice. Cellular proliferation is significantly increased in mammary adenocarcinomas as compared to mammary dysplastic lesions within each genotype. Data are presented as mean proliferative index \pm s.e.m. and significance comparisons were conducted by ANOVA and Scheffe post hoc testing: a $(P=0.048), b$ $(P=0.024)$, and $c(P=0.000 \mathrm{I})$. (Inset) Histological image of $\mathrm{H}+\mathrm{E}$-stained mammary section with black arrowhead indicating a representative mitotic figure.

Loss of allelic bax does not alter cellular proliferation in mammary tumours from parous MMTV-c-myc transgenic mice

Proliferative indices were generated for both mammary adenocarcinomas and peritumorous dysplastic lesions by counting mitotic figures on mammary tumour and tissue sections. As shown in Figure 4, proliferation was not significantly altered in either mammary adenocarcinomas or dysplastic mammary lesions with loss of allelic bax in parous MMTV-c-myc study mice. Within each genotype, there was significantly more cellular proliferation in mammary adenocarcinomas as compared with peritumorous dysplastic mammary lesions $(2.03 \pm 0.58$ vs $0.49 \pm 0.005$ for $m y c$ $b a x+I+, P=0.048 ; 1.55 \pm 0.17$ vs $0.23 \pm 0.05$ for $m y c b a x+I-$, $P=0.024$; and $1.60 \pm 0.06$ vs $0.20 \pm 0.09$ for myc bax $-/-, P=0.0001$ ).

\section{DISCUSSION}

The exogenous expression of murine c-myc using the MMTV-LTR promoter system has previously been demonstrated to induce mammary tumorigenesis; furthermore, these mammary tumours are characterised by a significantly elevated apoptotic index (Stewart et al, 1984; Amundadottir et al, 1996). Results from the MMTV-c-myc/MT-tgf $\alpha$ bitransgenic mammary tumour model suggest that a diminution of in vivo apoptosis can accentuate cMyc-induced mammary tumour formation (Amundadottir et al, 1995). The Bax protein is known to be a key mitochondrial regulator of apoptosis and has been shown to be a transcriptional target of c-Myc (Mitchell et al, 2000). In this latter capacity, Bax may be responsible, in part, for apoptosis resulting from deregulated c-myc expression and its loss in human breast tumours may eliminate c-Myc's potential tumour suppressive role. In this study, bax-knockout and MMTV-c-myc transgenic mice were mated to generate a mammary-relevant model in which the influence of the loss of bax on c-Myc-induced apoptosis and tumorigenesis could be investigated. Our results clearly demonstrate that loss of bax is directly and significantly correlated with a reduction in apoptosis in mammary adenocarcinomas. 
Furthermore, haploid loss of bax, in the context of MMTV-c-myc expression, results in an elevation in mammary tumour multiplicity without influencing mammary tumour latency or histopathology. However, in contradistinction to prior findings for c-Myc-mediated lymphomagenesis (Eischen et al, 2001a), complete loss of bax did not promote c-Myc-induced mammary tumorigenesis, suggesting that some amount of Bax expression is required for mammary tumorigenesis.

Previous studies have reported the incidence of mammary tumours in single strain, multiparous MMTV-c-myc mice as approaching $100 \%$; however, no studies of MMTV-c-myc transgenic or myc-containing bitransgenic mice have reported mammary tumour multiplicity findings (Stewart et al, 1984; Jamerson et al, 2000). In our study of multiparous, multistrain MMTV-c-myc transgenic mice possessing both wild-type bax alleles, the incidence of mammary tumours was $20 \%$ and the multiplicity was one tumour per mouse. This reduced mammary tumour incidence identified in our studies for c-myc transgenic mice may reflect the tumour suppressive influences of a mixed-strain background in our mouse model or may represent functional changes in the genetic control of the c-myc transgene itself. Significantly, other studies have concluded that alteration of or mixing of inbred genetic backgrounds can significantly influence transgene-induced mammary tumorigenesis (Griep et al, 1998; Lifsted et al, 1998; Rowse et al, 1998; Le Voyer et al, 2000; RoseHellekant et al, 2002). The C57BL/6 XFVB cross utilised in the current study has been previously studied in this respect, implicating C57BL/6 as bearing an unknown mammary tumour penetrance-modifying influence (Rose-Hellekant et al, 2002). Although the c-Myc penetrance-modifier in our study remains unknown, methylation of the MMTV-LTR promotional element, silencing of linked transgene expression, and abrogation of transgene-dependent tumorigenesis has been described previously (Mangues et al, 1995; Betzl et al, 1996; Zhou et al, 2001). Additionally, MMTV-LTR methylation patterns are heterogeneous among offspring from the same litter and promoter demethylation appears to be required for transgene-driven tumorigenesis. The reduced mammary tumour incidence in our study animals may result from methylation of the MMTV-c-myc transgene and concomitant reduction or elimination of $\mathrm{c}-\mathrm{Myc}$ protein expression. Analysis of $\mathrm{c}-\mathrm{Myc}$ protein expression in mammary gland and tumour lysates confirms that c-Myc expression is limited to the mammary adenocarcinomas and is below the sensitivity of this assay in the nontumorous mammary glands from c-myc transgenepositive and transgene-negative mice. These data suggest that functional changes in the genetic or epigenetic control of c-myc transgene expression may be responsible for the diminished penetrance of the mammary tumour phenotype in our studies.

Evaluation of mammary gland whole mounts from tumourbearing and nontumour-bearing study mice revealed a definite correlation between the presence of multiple hyperplastic alveolar nodules and the presence of $c-m y c$ transgene expression and mammary adenocarcinomas. The absence of mammary gland hyperplastic changes, as assessed by whole mount, in animals that do not express the c-myc transgene lends credence to the idea that the transforming influence of $c-m y c$ transgene expression is required for hyperplastic, dysplastic, and neoplastic changes in the mammary gland in this model. In tumour-bearing mice, the presence of transgene-induced glandular changes at the whole mount level is confirmed by the identification of mammary gland dysplastic changes at the microscopic histopathological level. As expected, and independent of the status of bax in our study mice, a cribiform mammary adenocarcinoma phenotype was identified. Evaluation of the mammary gland pathology of genetically engineered mice has shown that the $c-m y c$ transgene-induced adenocarcinomas are characterised by a cribiform phenotype that is dominantly expressed when the c-myc transgene is co-expressed with other transgenes (Cardiff et al, 2000). Therefore, our findings revealed the transforming role of the c-myc transgene in our tumour model and have suggested that expression of the cribiform tumour phenotype is not abrogated by elimination of the bax tumour suppressor gene.

As anticipated for an apoptosis-regulatory gene, loss of wild-type bax alleles did not significantly alter proliferation, in both mammary adenocarcinomas and dysplastic mammary tissue, in tumourbearing MMTV-c-myc mice. Our results did demonstrate a significant increase in cellular proliferation between dysplastic mammary tissues and mammary adenocarcinomas, as might be expected in the progression of mammary lesions. As expected with the loss of the proapoptotic bax gene, a trend toward diminished apoptosis in dysplastic mammary tissue and a significant diminution in apoptosis in mammary adenocarcinomas was identified in tumour-bearing MMTV-c-myc mice with loss of one and both wildtype alleles of bax. Our studies also demonstrate that haploid loss of bax is associated with an increase in mammary tumour multiplicity in multiparous MMTV-c-myc study mice; intriguingly however, complete loss of the wild-type bax alleles results in a mammary tumour multiplicity, but not incidence identical to that for mice with intact bax. These results, of bax loss influencing mammary gland apoptosis and mammary tumour multiplicity, but not incidence, are similar, but not identical, to those seen for the C(3)1/SV40-Tag/baxknockout mice (Shibata et al, 1999). Characterisation of baxhemizygous and bax-nullizygous mice expressing the C(3)1-Tag transgene resolved that selectively in hemizygous bax animals, apoptosis was significantly reduced in preneoplastic mammary lesions with subsequent enhancement of tumour number (Shibata et al, 1999). No such enhancement in SV40-dependent mammary tumorigenesis was observed in bax-nullizygous mice. The reductions in c-Myc-mediated mammary tumour multiplicity and incidence seen in our bax-nullizygous mice are similar to the findings reported from this previous study and may reflect mammary gland hypoplasia resulting from loss of both wild-type alleles of bax (Shibata et al, 1999). It is worth considering that Bax may have a stage-specific role in suppressing c-Myc-mediated mammary tumorigenesis (apoptosis suppression with bax loss is differentially stage-specific with respect to the inducer of apoptosis, Myc or TAg). Notably, as indicated earlier in the introduction, Bax loss strongly enhances c-Myc-dependent lymphomagenesis (Eischen et al, 2001a). It should be noted that c-Myc-dependent lymphomagenesis is also strongly enhanced in the absence of one or both p53 alleleles, in contrast to mammary tumorigenesis. (Elson et al, 1995, McCormack et al, 1998). Since c-Myc-dependent mammary tumours seldom contain mutated p53, in striking contrast to lymphomas, future studies could productively address the interactions between $\mathrm{p} 53$ and Bax in distinguishing differential, c-Myc effects on tumorigenesis in these two tissue types.

In conclusion, haploid loss of bax in multiparous MMTV-c-myc transgenic mice is associated with a significantly decreased mammary tumour apoptotic index. Loss of bax is not associated with alterations in mammary tumour proliferation. Our results indicate that bax is involved in the regulation of apoptosis in tumours of the murine mammary gland and may be, at best, a weakly negative modulator of c-Myc-mediated mammary tumorigenesis. Complete loss of bax, associated with the most significant suppression of apoptosis in mammary tumours in our model, is clearly not associated with suppression of mammary tumorigenesis, as compared with loss of one wild-type allele of bax. This finding suggests that Bax may be required for mammary tumour development at some stage, and that the contribution of other apoptotic pathways may be important to mammary tumorigenesis in our model. These results are the first published that demonstrate that haploid loss of bax, as seen in many human breast cancers, significantly reduces mammary tumour apoptosis provoked by a human breast cancer-relevant proto-oncogene, c-myc. Our results clearly show that in contrast to the role of Bax as a proapoptotic tumour suppressor in c-Myc-induced 
lymphomogenesis (Eischen et al, 2001a), in c-Myc-dependent mammary tumorigenesis Bax is proapoptotic, but lacking in significant mammary tumour suppressive activity.

\section{ACKNOWLEDGEMENTS}

We would like to express sincere gratitude to Dr Jeff Green of the Laboratory of Cell Regulation and Carcinogenesis, National
Cancer Institute, for pathological review, technical discussions and critical review of the manuscript. We also thank Ms Yin Zhang for assistance with statistical analyses. Matthew Hunter Jamerson was a $\mathrm{PhD}$ student financially supported by the US Army Breast Cancer Research Program Pre-Doctoral Fellowship DAMD17-97-1-7110 and the Georgetown University Institutional Tumor Biology Training grant (2T32CA09686). NIH grants 1R01AG1496 and 1R01CA72460 to Dr Robert Dickson also supported this work.

\section{REFERENCES}

Amundadottir LT, Johnson MD, Merlino G, Smith GH, Dickson RB (1995) Synergistic interaction of transforming growth factor alpha and c-myc in mouse mammary and salivary gland tumorigenesis. Cell Growth Diff 6: $737-748$

Amundadottir LT, Nass SJ, Berchem GJ, Johnson MD, Dickson RB (1996) Cooperation of TGF alpha and c-Myc in mouse mammary tumorigenesis: coordinated stimulation of growth and suppression of apoptosis. Oncogene 13: 757-765

Antonsson B, Conti F, Ciavetti A, Montessuit S, Lewis S, Martinou I, Bernasconi L, Bernard A, Mermod JJ, Mazzei G, Maundrell K, Gambale F, Sadoul R, Martinou JC (1997) Inhibition of Bax channel-forming activity by Bcl-2. Science 277: $370-372$

Antonsson B, Montessuit S, Lauper S, Eskes R, Martinou JC (2000) Bax oligomerization is required for channel-forming activity in liposomes and to trigger cytochrome $c$ release from mitochondria. Biochem $J$ 345: $271-278$

Bargou RC, Daniel PT, Mapara MY, Bommert K, Wagener C, Kallinich B, Royer HD, Dörken B (1995) Expression of the Bcl-2 gene family in normal and malignant breast tissue: low Bax-alpha expression in tumor cells correlates with resistance towards apoptosis. Int $J$ Cancer $\mathbf{6 0}$ 854-859

Bargou RC, Wagener C, Bommert K, Mapara MY, Daniel PT, Arnold W, Dietel M, Guski H, Feller A, Royer HD, Dörken B (1996) Overexpression of the death-promoting gene Bax-alpha which is downregulated in breast cancer restores sensitivity to different apoptotic stimuli and reduces tumor growth in SCID mice. J Clin Invest 97: 2651-2659

Bates SE, Valverius EM, Ennis BW, Bronzert DA, Sheridan JP, Stampfer MR, Mendelsohn J, Lippman ME, Dickson RB (1990) Expression of the transforming growth factor-alpha/epidermal growth factor receptor pathway in normal human breast epithelial cells. Endocrinology 126: $596-607$

Betzl G, Brem G, Weidle UH (1996) Epigenetic modification of transgenes under the control of the mouse mammary tumor virus LTR: tissuedependent influence on transcription of the transgenes. Biol Chem 377: $711-719$

Cardiff RD, Anver MR, Gusterson BA, Hennighausen L, Jensen RA, Merino MJ, Rehm S, Russo J, Tavassoli FA, Wakefield LM, Ward JM, Green JE (2000) The mammary pathology of genetically engineered mice: the Consensus report and recommendations from the Annapolis meeting. Oncogene 19: 968 - 988

D'Cruz CM, Gunther DJ, Boxer RB, Hartman JL, Sintasath L, Moody SE Cox JD, Ha SI, Belka GK, Golant A, Cardiff RD, Chodosh LA (2001) c-Myc induces mammary tumorigenesis by means of a preferred pathway involving spontaneous Kras2 mutations. Nat Med 7: $235-239$

Dang CV (1999) c-Myc target genes involved in cell growth, apoptosis and metabolism. Mol Cell Biol 19: 1-11

Deming SL, Nass SJ, Dickson RB, Trock BJ (2000) c-Myc amplification in breast cancer: a meta-analysis of its occurrence and prognostic relevance. Br J Cancer 83: 1688 - 1695

Desagher S, Osen-Sand A, Nichols A, Eskes R, Montessuit S, Lauper S, Maundrell K, Antonsson B, Martinou JC (1999) Bid-induced conformational change of Bax is responsible for mitochondrial cytochrome $c$ release during apoptosis. J Cell Biol 144: 891-901

Eischen CM, Rehg JE, Korsmeyer SJ, Cleveland JL (2002) Loss of Bax alters tumor spectrum and tumor numbers in ARF-deficient mice. Cancer Res 62: $2184-2191$

Eischen CM, Roussel MF, Korsmeyer SJ, Cleveland JL (2001a) Bax loss impairs c-Myc-induced apoptosis and circumvents the selection of p53 mutations during Myc-mediated lymphomagenesis. Mol Cell Biol 22: $7653-7662$

Eischen CM, Woo D, Roussel MF, Cleveland JL (2001b) Apoptosis triggered by Myc-induced suppression of $\mathrm{Bcl}-\mathrm{xL}$ or $\mathrm{Bcl}-2$ is bypassed during lymphomagenesis. Mol Cell Biol 21: 5063-5070

Elson A, Deng C, Campos-Torres J, Donchower LA, Leder P (1995) The $\mathrm{MMTV} / \mathrm{c}-\mathrm{myc}$ transgene and $\mathrm{p} 53$ null alleles collaborate to induce T-cell lymphomas, but not mammary carcinomas in transgenic mice. Oncogene 11: $181-190$

Evan GI, Littlewood TD (1993) The role of c-Myc in cell growth. Curr Opin Genet Dev 3: $44-49$

Evan GI, Wyllie AH, Gilbert CS, Littlewood TD, Land H, Brooks M, Waters CM, Penn LZ, Hancock DC (1992) Induction of apoptosis in fibroblasts by c-Myc protein. Cell 69: $119-128$

Felsher DW, Bishop JM (1999a) Transient excess of Myc activity can elicit genomic instability and tumorigenesis. Proc Natl Acad Sci USA 96: $3940-3944$

Felsher DW, Bishop JM (1999b) Reversible tumorigenesis by Myc in hematopoietic lineages. Mol Cell 4: 199-207

Feuerhake F, Sigg W, Höfter EA, Dimpfl T, Welsch U (2000) Immunohistochemical analysis of $\mathrm{Bcl}-2$ and Bax expression in relation to cell turnover and epithelial differentiation markers in the non-lactating human mammary gland epithelium. Cell Tissue Res 299: 47-58

Griep AE, Krawcek J, Lee D, Liem A, Albert DM, Carabeo R, Drinkwater N, McCall M, Sattler C, Lasudry JG, Lambert PF (1998) Multiple genetic loci modify risk for retinoblastoma in transgenic mice. Invest Ophthalmol Vis Sci 39: $2723-2732$

Harrington EA, Bennett MR, Fanidi A, Evan GI (1994) c-Myc-induced apoptosis in fibroblasts is inhibited by specific cytokines. EMBO J 13: $3286-3295$

Jäger R, Herzer U, Schenkel J, Weiher H (1997) Overexpression of Bcl-2 inhibits alveolar cell apoptosis during involution and accelerates c-mycinduced tumorigenesis of the mammary gland in transgenic mice. Oncogene 15: 1787-1795

Jamerson MH, Johnson MD, Dickson RB (2000) Dual regulation of proliferation and apoptosis: $\mathrm{c}-m y c$ in bitransgenic murine mammary tumor models. Oncogene 19: 1065-1071

Jhappan C, Stahle C, Harkins RN, Fausto N, Smith GH, Merlino GT (1990) TGF-alpha overexpression in transgenic mice induces liver neoplasia and abnormal development of the mammary gland and pancreas. Cell 61 : $1137-1146$

Juin P, Hueber AO, Littlewood T, Evan GI (1999) c-Myc-induced sensitization to apoptosis is mediated through cytochrome $\mathrm{c}$ release. Genes Dev 13: $1367-1381$

Juin P, Hunt A, Littlewood T, Griffiths B, Swigart LB, Korsmeyer SJ, Evan GI (2002) c-Myc functionally cooperates with Bax to induce apoptosis. Mol Cell Biol 22: 6158-6169

Jurgensmeier JM, Xie Z, Deveraux Q, Ellerby L, Bredesen D, Reed JC (1998) Bax directly induces release of cytochrome $c$ from isolated mitochondria. Proc Natl Acad Sci USA 95: 4997-5002

Kapranos N, Karaiosifidi H, Valavanis C, Kouri E, Vasilaros S (1997) Prognostic significance of apoptosis related proteins Bcl-2 and Bax in node-negative breast cancer patients. Anticancer Res 17: 24992506

Knudson CM, Tung KSK, Tourtellotte WG, Brown GAJ, Korsmeyer SJ (1995) Bax-deficient mice with lymphoid hyperplasia and male germ cell death. Science 270: 96-99

Krajewski S, Blomqvist C, Franssila K, Krajewska M, Wasenius VM, Niskanen E, Nordling S, Reed JC (1995) Bcl-2 family proteins and the 
regulation of programmed cell death in leukemia and lymphoma. Cancer Res 55: $4471-4478$

Krajewski S, Krajewska M, Shabaik A, Miyashita T, Wang HG, Reed JC (1994) Immunohistochemical determination of the in vivo distribution of Bax, a dominant inhibitor of Bcl-2. Am J Pathol 145: 1323-1336

Le Voyer T, Lu Z, Babb J, Lifsted T, Williams M, Hunter KW (2000) An epistatic interaction controls the latency of a transgene-induced mammary tumor. Mamm Genome 11: 883-889

Leder A, Pattengale PK, Kuo A, Stewart TA, Leder P (1986) Consequences of widespread deregulation of the c-Myc gene in transgenic mice: multiple neoplasms and normal development. Cell 45: 485-495

Li M, Hu J, Heermeier K, Hennighausen L, Furth PA (1996) Apoptosis and remodeling of mammary gland tissue during involution proceeds through p53-independent pathways. Cell Growth Diff 7: 13-20

Lifsted T, Le Voyer T, Williams M, Muller W, Klein-Szanto A, Buetow KH, Hunter KW (1998) Dentification of inbred mouse strains harboring genetic modifiers of mammary tumor age of onset and metastatic progression. Int J Cancer 77: 640-644

Mangues R, Schwartz S, Seidman I, Pellicer A (1995) Promoter demethylation in MMTV/N-ras transgenic mice required for transgene expression and tumorigenesis. Mol Carcinogen 14: 94-102

Matsui Y, Halter SA, Holt JT, Hogan BLM, Coffey RJ (1990) Development of mammary hyperplasia and neoplasia in MMTV-TGF alpha transgenic mice. Cell 61: 1147-1155

McCormack SJ, Weaver Z, Deming S, Natarajan G, Torri J, Johnson MD, Liyanage M, Ried T, Dickson RB (1998) Myc/p53 interactions in transgenic mouse mammary development, tumorigenesis, and chromosal instability. Oncogene 16: $2755-2766$

Mitchell KO, Ricci MS, Miyashita T, Dicker DT, Jin Z, Reed JC, El-Deiry WS (2000) Bax is a transcriptional target and mediator of c-Myc-induced apoptosis. Cancer Res 60: 6318-6325

Murphy KM, Streips UN, Lock RB (1999) Bax membrane insertion during Fas(CD95)-induced apoptosis precedes cytochrome $c$ release and is inhibited by Bcl-2. Oncogene 18: 5991-5999

Nass SJ, Dickson RB (1997) Defining a role for c-Myc in breast tumorigenesis. Breast Cancer Res Treat 44: 1-22

Nouraini S, Six E, Matsuyama S, Krajewski S, Reed JC (2000) The putative pore-forming domain of Bax regulates mitochondrial localization and interaction with Bcl-xL. Mol Cell Biol 20: 1604-1615

Oltvai ZN, Milliman CL, Korsmeyer SJ (1993) Bcl-2 heterodimerizes in vivo with a conserved homolog, Bax, that accelerates programmed cell death. Cell 74: 609-619

Packham G, Cleveland JL (1995) c-Myc and apoptosis. Biochim Biophys Acta 1242: 11-28

Prendergast GC (1999) Mechanisms of apoptosis by c-Myc. Oncogene 18: $2967-2987$

Rose-Hellekant TA, Gilchrist K, Sandgren EP (2002) Strain background alters mammary gland lesion phenotype in transforming growth factor-a transgenic mice. Am J Pathol 161: 1439-1447

Rowse GJ, Ritland SR, Gendler SJ (1998) Genetic modulation of neu protooncogene-induced mammary tumorigenesis. Cancer Res 58: 2675-2679

Sakakura C, Sweeney EA, Shirahama T, Igarashi Y, Hakomori S, Nakatani $\mathrm{H}$, Tsujimoto $\mathrm{H}$, Imanishi $\mathrm{T}$, Ohgaki $\mathrm{M}$, Ohyama $\mathrm{T}$, Yamazaki J, Hagiwara A, Yamaguchi T, Sawai K, Takahashi T (1996) Overexpression of Bax sensitizes human breast cancer MCF-7 cells to radiation-induced apoptosis. Int J Cancer 67: $101-105$

Sandgren EP, Luetteke NC, Palmiter RD, Brinster RL, Lee DC (1990) Overexpression of TGF alpha in transgenic mice: induction of epithelial hyperplasia, pancreatic metaplasia, and carcinoma of the breast. Cell 61: $1121-1135$

Sandgren EP, Schroeder JA, Qui TH, Palmiter RD, Brinster RL, Lee DC (1995) Inhibition of mammary gland involution associated with transforming growth factor $\alpha$ but not c-myc-induced tumorigenesis in transgenic mice. Cancer Res 55: 3915-3927

Santoni-Rugiu E, Jensen MR, Thorgeirsson SS (1998) Disruption of the $\mathrm{pRb} / \mathrm{E} 2 \mathrm{~F}$ pathway and inhibition of apoptosis are major oncogenic events in liver constitutively expressing c-Myc and transforming growth factor alpha. Cancer Res 58: 123 - 134

Schorr K, Li M, Bar-Peled U, Lewis A, Heredia A, Lewis B, Knudson CM, Korsmeyer SJ, Jäger R, Weiher H, Furth PA (1999a) Gain of Bcl-2 is more potent than Bax loss in regulating mammary epithelial cell survival in vivo. Cancer Res 59: $2541-2545$

Schorr K, Li M, Krajewski S, Reed JC, Furth PA (1999b) Bcl-2 gene family and related proteins in mammary gland involution and breast cancer. J Mamm Gland Biol Neoplasia 4: 153-164

Shibata MA, Liu ML, Knudson MC, Shibata E, Yoshidome K, Bandey T, Korsmeyer SJ, Green JE (1999) Haploid loss of Bax leads to accelerated mammary tumor development in C3(1)/SV40-Tag transgenic mice: reduction in protective apoptotic response at the preneoplastic stage. EMBO J 18: $2692-2701$

Shilkaitis A, Graves J, Mehta RR, Hu L, You M, Lubet R, Steele V, Kelloff G, Christov K (2000) Bcl-2 and bax are differentially expressed in hyperplastic, premalignant, and malignant lesions of mammary carcinogenesis. Cell Growth Diff 11: 437-445

Sjöström J, Krajewski S, Franssila K, Niskanen E, Wasenius VM, Nordling S, Reed JC, Blomqvist C (1998) A multivariate analysis of tumour biological factors predicting response to cytotoxic treatment in advanced breast cancer. $\mathrm{Br}$ J Cancer 78: 812-815

Snedeker SM, Brown CF, DiAugustine RP (1991) Expression and functional properties of transforming growth factor alpha and epidermal growth factor during mouse mammary gland ductal morphogenesis. Proc Natl Acad Sci USA 88: 276-280

Soucie EL, Annis MG, Sedivy J, Filmus J, Leber B, Andrews DW, Penn LZ (2001) Myc potentiates apoptosis by stimulating Bax activity at the mitochondria. Mol Cell Biol 21: 4725-4736

Stewart TA, Pattengale PK, Leder P (1984) Spontaneous mammary adenocarcinomas in transgenic mice that carry and express $\mathrm{MTV} / \mathrm{myc}$ fusion genes. Cell 38: $627-637$

Strange R, Li F, Saurer S, Burkhardt A, Friis RR (1992) Apoptotic cell death and tissue remodeling during mouse mammary gland involution. Development 115: 49-58

Telang NT, Osborne MP, Sweterlitsch LA, Narayanan R (1990) Neoplastic transformation of mouse mammary epithelial cells by deregulated Myc expression. Cell Regul 1: 863-872

Valverius EM, Ciardiello F, Heldin NE, Blondel B, Merlo G, Smith GH, Stampfer MR, Lippman ME, Dickson RB, Salomon DS (1990) Stromal influences on transformation of human mammary epithelial cells overexpressing c-Myc and SV40T. J Cell Physiol 145: 207-216

Vennstrom B, Sheiness D, Zabielski J, Bishop JM (1982) Isolation and characterization of c-Myc, a cellular homolog of the oncogene (v-Myc) of avian myelocytomatosis virus strain 29. J Virol 42: 773-779

Weaver ZA, McCormack SJ, Liyanage M, du Manoir S, Coleman A, Schröck E, Dickson RB, Ried T (1999) A recurring pattern of chromosomal aberrations in mammary gland tumors of MMTV-c-myc transgenic mice. Genes Chromosome Cancer 25: 251-260

Wei MC, Zong WX, Cheng EHY, Lindsten T, Panousakopoulou V, Ross AJ, Roth KA, MacGregor GR, Thompson CB, Korsmeyer SJ (2001) Proapoptotic BAX and BAK: a requisite gateway to mitochondrial dysfunction and death. Science 292: 727-730

Workman P, Twentyman P, Balkwill F, Balmain A, Chaplin D, Double J, Embleton J, Newell D, Raymond R, Stables J, Stephens T, Wallace J (1998) United Kingdom Co-ordinating Committee on Cancer Research (UKCCCR) Guidelines for the Welfare of Animals in Experimental Neoplasia (Second Edition). Br J Cancer 77: 1 - 10

Zhou H, Chen W, Qin X, Lee K, Liu L, Markowitz SD, Gerson SL (2001) MMTV promoter hypomethylation is linked to spontaneous and MNUassociated c-neu expression and mammary carcinogenesis in MMTV-cneu transgenic mice. Oncogene 20: 6009-6017

Zindy F, Eischen CM, Randle DH, Kamijo T, Cleveland JL, Sherr CJ, Roussel MF (1998) Myc signaling via the ARF tumor suppressor regulates p53-dependent apoptosis and immortalization. Genes Dev 12: $2424-2433$ 